\title{
RETRIEVAL OF 24 HOUR AEROSOL OPTICAL DEPTHS FROM MIE LIDAR DATA
}

\author{
${ }^{1}$ Siriluk Ruangrungrote, ${ }^{1,2}$ Pichet Limsuwan and ${ }^{3}$ Arunee Intasorn
}

\author{
${ }^{1}$ Department of Physics, Faculty of Science, \\ King Mongkut's University of Technology Thonburi, Bangkok 10140, Thailand \\ ${ }^{2}$ Thailand Center of Excellence in Physics, CHE, Ministry of Education, Bangkok 10400, Thailand \\ ${ }^{3}$ Department of Physics, Faculty of Science, Srinakharinwirot University, Bangkok 10110, Thailand
}

Received 2012-08-22, Revised 2013-07-11; Accepted 2013-07-19

\begin{abstract}
Temporal Aerosol Optical Depths (AODs) of Phimai district, Nakhon Ratchasima province in Thailand were retrieved from measured Mie lidar data on 17-20 February 2005 using Fernald method. The groundbased station was selected for its high and diverse local agricultural activities contributed to the aerosol content which allows for various parameters such as concentration, size distribution and aerosol optical properties to be investigated by Mie theory. The retrieval algorithm of $24 \mathrm{~h}$ AODs was performed in order to monitor regional impact of biomass burning emission on tropospheric aerosols. Results revealed that open biomass burning was a significant contributor to large carbonaceous aerosols in the vicinity of research site with AOD around 0.6-0.7. Furthermore, the prominence of open burning emission yielded short range aerosol transportation when fine and coarse aerosol particles were accumulated with the minimum and maximum average AODs of 0.2187 and 0.4291 , respectively. In addition, the observation provided important insights into the physical and scavenging of aerosols under the influence of regional anthropogenic source and would be great knowledge of aerosol data development. By the lidar technique used in present work, the nocturnal AOD retrieval was advantageously available.
\end{abstract}

Keywords: Fernald Method, Lidar Technique, Aerosol Optical Depths, Biomass Burning

\section{INTRODUCTION}

During the past century, the amount of carbon dioxide in the atmosphere has increased by about $25 \%$ on account of human activities (fossil fuel/biomass burning) (IPCC, 1995; Meehl et al., 1996). This has caused the surface temperature of the Earth to increase globally by about one Kelvin (Satheesh and Moorthy, 2005). In the recent years, both direct and indirect radiative influences of aerosols have continued to be one of the most significant sources of uncertainty in climate change. Also, changes in the greenhouse gas and aerosol content of the atmosphere affect the radiation balance of the climate system, it then will be useful for global environmental monitoring studies of anthropogenic aerosols especially by considering both their optical and physical properties.
Atmospheric aerosol optical depth is an important parameter for studies of atmospheric pollution, aerosol radiation-climate effects and so on (Qiu, 1998). Aerosol Optical Depth (AOD) is the extinction of light caused by atmospheric aerosols which exist in a variety of forms such as dust, fume and mist (Linyan et al., 2008). AOD shows large spatial and temporal variations because of the various production, transport and removal processes and the prevailing meteorological conditions. Its values are related to concentration, size distribution and aerosol optical properties, since aerosol scattering varies in complicated manner depending on size distribution and indices of refraction of the aerosol particles (Iokibe et al., 2005). It truly has an impact on climate and land surface environment in both regional and global scales, while 
tropospheric aerosols, e.g., carbonaceous (black carbon and organic carbon), sulfate and soil dust have more influence on human health. On global basis, major source of carbonaceous aerosol is biomass burning (Reddy et al., 2002). It is the burning of living and dead vegetation which includes the human-initiated burning for land clearing. Scientists estimate that humans are responsible for about $90 \%$ of biomass burning which releases large amount of particulates (solid carbon combustion particles) and gases, including greenhouse gas that helps warm the earth. Studies suggest that biomass burning has increased on a global scale over the last 100 years (NASA, 2001), yielding the deep impact on climate and human being.

Many methods have been proposed to retrieve AOD, several ground-based networks for aerosol optical properties have been operated in East Asia (Kim et al., 2007) such as Aerosol Robotic Network (AERONET) sun/sky radiometer, SKYNET and the Asian Dust lidar Network (using Micro-Pulse lidar: MPL). Due to the direct aerosol effect on the earth's radiation budget in absorbing and scattering solar radiation, the investigation of AOD is usually performed during daytime using sunphotometer. However, the indirect aerosol effect plays a key role in physical and radiative properties of clouds. lidar technology is now mature enough to provide quantitative measurements of the optical properties of aerosols with high spatial and temporal resolutions and with a high level of accuracy (Pappalardo et al., 2003). Recently, lidar is widely used as a tool for remote sensing of atmospheric aerosols and clouds (Reagan et al., 1989).

\section{MATERIALS AND METHODS}

Although, there are several instruments for providing aerosol optical depth values, here in Thailand the lacks of instrumentation and available database for aerosol observation are persisted and constrained. The capability of Mie scattering lidar system installed in Phimai district, Nakhon Ratchasima Province, Thailand allows tropospheric aerosol observation from $6 \mathrm{~m}$ to $24 \mathrm{~km}$ height over $24 \mathrm{~h}$. In the present work, we focus on AOD investigation for both diurnal and nocturnal periods particularly in the lower troposphere $(0-4 \mathrm{~km})$ whereas aerosols are condensed. The $24 \mathrm{hr}$ dataset of 4 consecutive days during 17-20 February 2005 were selected because the farmers started the open biomass burning of agricultural wastes during harvest season, causing large amount of carbonaceous and soil dust aerosols which was suitable to initially analyze clear and cloudy sky features and monitor aerosol optical property in Thailand.

\section{1. lidar System and Observation}

\subsubsection{Observation Site}

Figure 1 shows the location of Phimai district, Nakhon Ratchasima province $\left(15^{\circ} 13^{\prime} 0\right.$ " N, $102^{\circ} 30^{\prime} 0$ " E) where the lidar system was installed. It is about $300 \mathrm{~km}$ far-away from Bangkok. Phimai's major economic activity is agriculture in farming for example cassava, corn, rice, sugar cane and fruits. Due to 6-month long dry period and the local activities around Phimai, it is suitable for the anthropogenic aerosol study with an assumption that the man-made (biomass) burning is an important contributor to carbonaceous aerosol emission. Results of the retrieval of hourly instantaneous AODs from measured Mie lidar dataset (Ruangrungrote et al., 2008) had confirmed the reliability of retrieval algorithm and concluded that, there were extensive cassava cultivations as annual crop in Phimai region. It is also suggested that open biomass burning of agricultural wastes during harvest seasons can emit large amount of the mixture of carbonaceous and soil dust aerosols. Hence, the development of AOD retrieval database in Thailand is significantly required in order to observe nocturnal carbonaceous aerosol distribution and study their lifetimes in such region.

\subsection{Instrumentation}

Figure 2 shows the NIES Compact Mie scattering lidar system (Sugimoto, 2001) installed in Phimai, Nakhon Ratchasima province. The laser used in this lidar system is flashlamp pumped $\mathrm{Nd}$ : YAG laser with a second harmonic generator. A linearly polarized laser pulse with a wavelength of $532 \mathrm{~nm}$ is transmitted vertically into the atmosphere. The backscattered light from aerosols and clouds is received with a $20-\mathrm{cm}$ Schmidt Cassegrain telescope. The receiver has a polarizing beam splitter to separate the backscattered light into two components, parallel and perpendicular to the transmitted polarization. Separated polarization components are detected with the two photomultiplier tubes. The output from photomultipliers yields an electronic signal proportional to the received light intensity. Hence, the lidar measures the backscattered intensity, which contains information on atmospheric optical properties, including the depolarization ratio, indicating the non-sphericity of aerosol particles. 
Siriluk Ruangrungrote et al. / Physics International 4 (2): 88-96, 2013

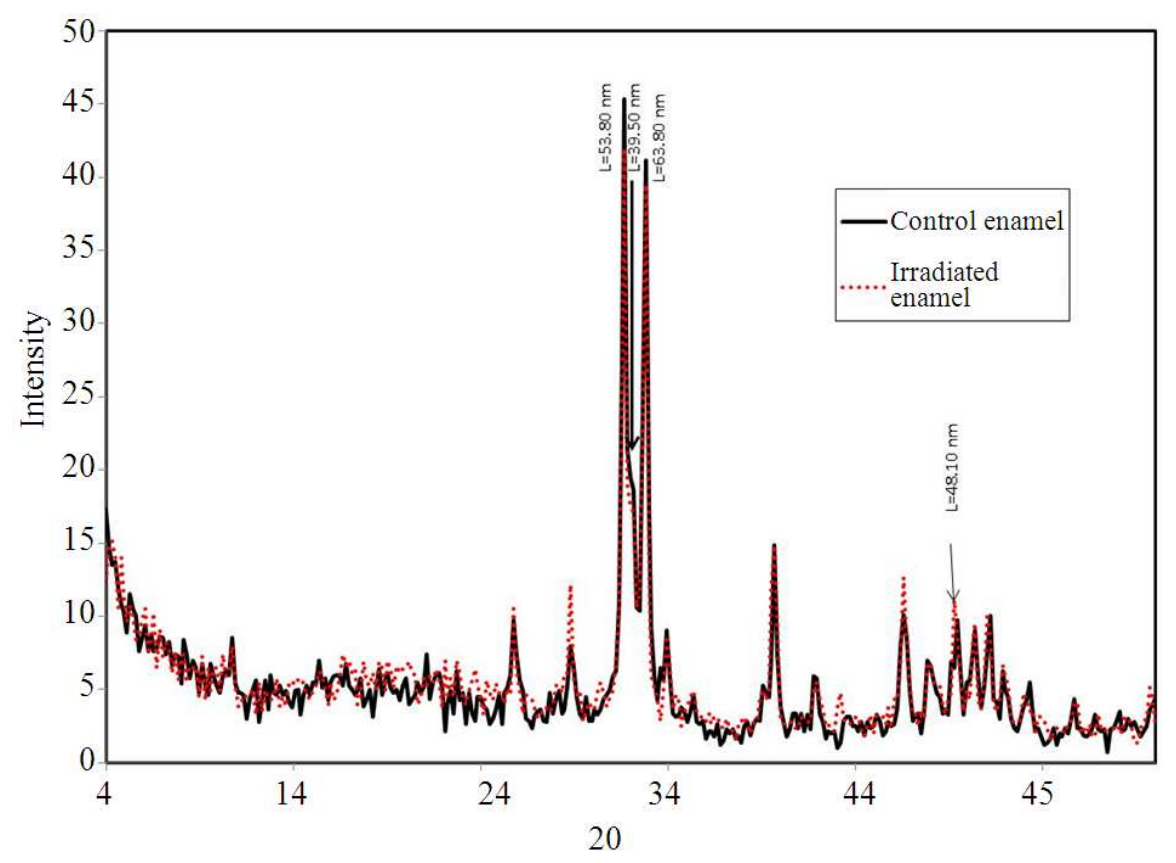

Fig. 1. The research site at Phimai district, Nakhon Ratchasima province

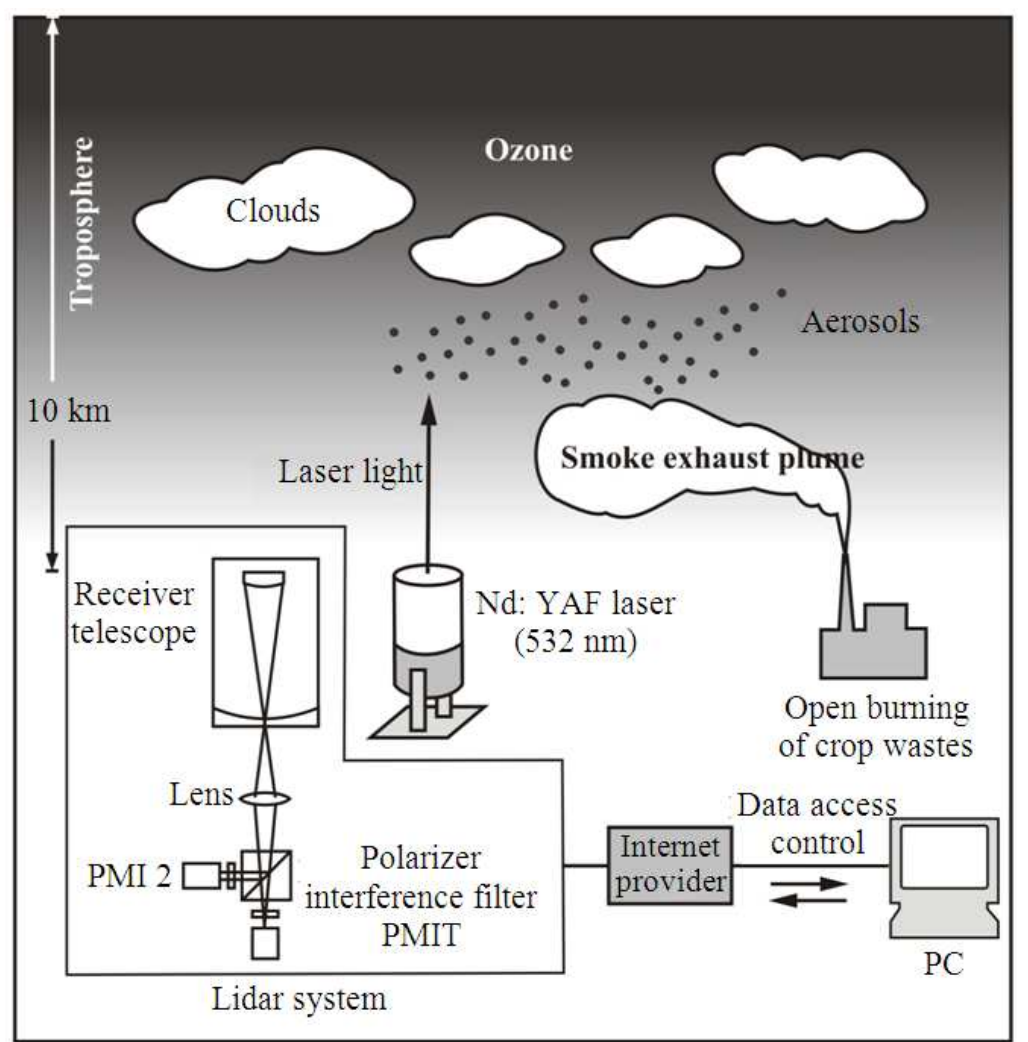

Fig. 2. Experimental setup for Mie scattering lidar 
Mie scattering lidar was operated for a period of 5 min for every $15 \mathrm{~min}$. After $5 \mathrm{~min}$ observation, the data was stored on the hard disk of the PC. Data from $6 \mathrm{~m}$ to $24 \mathrm{~km}$ were recorded with $6 \mathrm{~m}$-height resolution over 24 $\mathrm{h}$ since most of atmospheric aerosol content is concentrated in the first few kilometers from ground level (Biral, 2003). The critical height $\left(\mathrm{z}_{\mathrm{c}}\right)$ which contains no aerosols, is suggested being as higher in the atmosphere as possible (Klett, 1985). Even though the consistency of aerosol observation can be performed from ground level up to stratosphere, the study of continental component as tropospheric aerosols was key objective. In this work, $\mathrm{z}_{\mathrm{c}}=15 \mathrm{~km}$ was designated for aerosol-free layer within tropopause (Ruangrungrote et al., 2008) and high fluctuation of noise signals were detected beyond such height. Therefore, average of all returned lidar signals above $z_{c}$ were calculated for a subtraction from the backscattered signals from $0-4 \mathrm{~km}$.

\subsection{Retrieval Algorithm}

\subsubsection{Particle Backscattering Coefficient}

For a single-wavelength pulsed lidar and a vertically pointing lidar, the single scattering lidar equation can be expressed in the form:

$$
\mathrm{P}(\mathrm{z})=\mathrm{ECz}^{-2}\left[\beta_{\mathrm{a}}(\mathrm{z})+\beta_{\mathrm{m}}(\mathrm{z})\right] \mathrm{T}_{\mathrm{a}}^{2}(\mathrm{z}) \mathrm{T}_{\mathrm{m}}^{2}(\mathrm{z})
$$

\section{Where:}

$\mathrm{P}(\mathrm{z})$

$\mathrm{E}$

C

\section{$\beta_{\mathrm{a}}(\mathrm{z})$}

$\beta_{\mathrm{m}}(\mathrm{z})$

$\mathrm{T}_{\mathrm{a}}(\mathrm{z})=\exp \left[-\int_{0}^{\mathrm{z}} \mathrm{a}_{\mathrm{a}}(\mathrm{z}) \mathrm{dz}\right]=$ Aerosol transmittance

$\mathrm{T}_{\mathrm{m}}(\mathrm{z})=\exp \left[-\int_{0}^{\mathrm{z}} \mathrm{a}_{\mathrm{m}}(\mathrm{z}) \mathrm{dz}\right]=$ Molecular

atmosphere

transmittance

$\mathrm{a}_{\mathrm{a}}(\mathrm{z})$ and $\mathrm{a}_{\mathrm{m}}(\mathrm{z})$ and $=$ Extinction cross sections of the aerosols and atmospheric molecules at height $\mathrm{z}$

The solution to Equation (1) for the aerosol backscattering coefficient $\beta_{\mathrm{a}}(\mathrm{z})$ can be determined using the Fernald method (Fernald et al., 1972; Fernald, 1984; Motoaki et al., 2002) and given by equation:

$$
\begin{aligned}
& \beta_{\mathrm{a}}(\mathrm{z})= \\
& \mathrm{P}(\mathrm{z}) \mathrm{z}^{2} \exp \\
& \frac{\left[-2\left(\mathrm{~S}_{\mathrm{a}}-\mathrm{S}_{\mathrm{m}}\right) \int_{0}^{\mathrm{z}} \beta_{\mathrm{m}}(\mathrm{z}) \mathrm{dz}\right]}{\mathrm{P}(\mathrm{z}) \mathrm{z}^{2} \exp }-\beta_{\mathrm{m}}(\mathrm{z}) \\
& C E-2 S_{a} \int_{0}^{z}\left[-2\left(S_{a}-S_{m}\right) \int_{0}^{z} \beta_{m}\left(z^{\prime}\right) d z^{\prime}\right] d z
\end{aligned}
$$

where, $\mathrm{S}_{\mathrm{a}}=\frac{\alpha_{\mathrm{a}}(\mathrm{z})}{\beta_{\mathrm{a}}(\mathrm{z})}$ and $\mathrm{S}_{\mathrm{m}}=\frac{\alpha_{\mathrm{m}}(\mathrm{z})}{\beta_{\mathrm{m}}(\mathrm{z})}=8 \pi / 3$ sr, are the lidar ratios for aerosol and molecule, respectively. The value of $\mathrm{S}_{\mathrm{a}}$ is assumed to be constant and independent of height in the calculation (Fernald, 1984). Here, the value of $\mathrm{S}_{\mathrm{a}}=35 \mathrm{sr}$ was used for dust aerosols (Karyampudi et al., 1999). Then, $a_{a}$ was calculated.

Now it is assumed that the aerosol backscattering coefficient at a specific height $\mathrm{z}_{\mathrm{c}}$ (calibration height), i.e., $\beta_{\mathrm{a}}\left(\mathrm{z}_{\mathrm{c}}\right)$ is known. Then, by solving Equation 2, the lidar equation can be expressed in the form:

$$
\begin{aligned}
& \beta_{\mathrm{a}}(\mathrm{z})+\beta_{\mathrm{m}}(\mathrm{z})= \\
& \frac{\mathrm{X}(\mathrm{z}) \exp \left[-2\left(\mathrm{~S}_{\mathrm{a}}-\mathrm{S}_{\mathrm{m}}\right) \int_{\mathrm{z}_{\mathrm{c}}}^{\mathrm{z}} \beta_{\mathrm{m}}(\mathrm{z}) \mathrm{dz}\right]}{\frac{\mathrm{X}\left(\mathrm{z}_{\mathrm{c}}\right)}{\beta_{\mathrm{a}}\left(\mathrm{z}_{\mathrm{c}}\right)+\beta_{\mathrm{m}}\left(\mathrm{z}_{\mathrm{c}}\right)}-} \\
& 2 \mathrm{~S}_{\mathrm{a}} \int_{\mathrm{z}_{\mathrm{c}}}^{\mathrm{z}} \mathrm{X}(\mathrm{z}) \exp \left[-2\left(\mathrm{~S}_{\mathrm{a}}-\mathrm{S}_{\mathrm{m}}\right) \int_{\mathrm{z}_{\mathrm{c}}}^{\mathrm{z}} \beta_{\mathrm{m}}\left(\mathrm{z}^{\prime}\right) \mathrm{dz}\right] \mathrm{dz}
\end{aligned}
$$

where, $X(z)=P(z) z^{2}$ is the range normalized signal at the heights $z_{c}$ and $z$.

In this study, $z_{c}$ is referred to critical height and set at $15 \mathrm{~km}$ which means that $\beta_{\mathrm{a}}\left(\mathrm{z}_{\mathrm{c}}\right)=0 \mathrm{~m}^{-1} \mathrm{sr}^{-1}$. Next, $\beta_{\mathrm{m}}\left(\mathrm{z}_{\mathrm{c}}\right)$ was calculated, yielding $\beta_{\mathrm{m}}(\mathrm{z})=\beta_{\mathrm{m}}\left(\mathrm{z}_{\mathrm{c}}\right)$ due to atmospheric homogeneity. By using Equation (3), $\beta_{\mathrm{a}}(\mathrm{z})$ could be obtained with the initial values of $S_{a}, S_{m}$ and the known X (z).

\subsection{Depolarization Ratio}

The linear depolarization ratio $\delta(z)$ is the ratio of perpendicular polarized signal to parallel polarized signal as given by Equation (4) (Iokibe et al., 2005):

$$
\delta(\mathrm{z})=\frac{\mathrm{P}_{\perp}(\mathrm{z})}{\mathrm{P}_{/ /}(\mathrm{z})}
$$


where, $P_{\perp}(z)$ and $P_{/ /}(z)$ are the received powers of the backscattered light (as a function of height $\mathrm{z}$ ) with linear polarization perpendicular and parallel, respectively, in respect of the transmitter polarization axis. The depolarization ratio is a measure of the non-sphericity of aerosol and cloud particles. Spherical particles like water droplets cause no depolarization ratio with $\delta=0$, whereas non-spherical particles, such as ice clouds and mineral dusts do produce depolarization, so that $\delta>0$.

Thus the depolarization ratio describes degree of polarization which can be used to distinguish aerosols from clouds and classify their types in atmospheric science applications. Clouds with $\delta<0.15$, are classified as water clouds. Depolarization ratio of clear air is low and affected by photon counting statistics, while depolarization ratio measurements are induced by presence of multiple scattering of dense clouds. The change from ice to water is noticeable as a drop in the depolarization ratio.

\subsection{Aerosol Optical Depth}

The aerosol lidar ratio $\left(\mathrm{S}_{\mathrm{a}}\right)$ is proposed to be constant and independent of height (Fernald, 1984). From the relation of $\mathrm{a}_{\mathrm{a}}(\mathrm{z})=\mathrm{S}_{\mathrm{a}}(\mathrm{z}) \beta_{\mathrm{a}}(\mathrm{z})$ where both values are known and assumed to be constant for every $6-\mathrm{m}$ height resolution, the $\mathrm{a}_{\mathrm{a}}(\mathrm{z})$ could be solved. Aerosol Optical Depth $\left(\tau_{\mathrm{a}}\right)$ corresponds to the path length $(\xi)$, defining in terms of Equation (5):

$$
\tau_{\mathrm{a}}=\int_{0}^{\xi} \alpha_{\mathrm{a}}(\mathrm{z}) \mathrm{dz}
$$

The condition of constant AOD for every 6-m height was also introduced to determine hourly $\tau_{\mathrm{a}}$. The vertical profiles of $\mathrm{X}(\mathrm{z}), \delta(\mathrm{z})$ and $\beta_{\mathrm{a}}(\mathrm{z})$ are plotted to indicate different features between cloud and aerosol for both clear and cloudy skies. Since the cloud layers have apparent sharp peak of all three parameters due to large multiple scattering, yielding the selective path length for aerosol region identification below cloud layers. Specifically, the maximum peak of aerosol backscattering coefficient could be used to analyze optimal path length for the implicit cloud appearance.

\section{RESULTS AND DISCUSSION}

Figure 3 shows the typical results of vertical profiles at a height below $4 \mathrm{~km}$ of $X(z), \delta(z)$ and $\beta_{\mathrm{a}}(\mathrm{z})$ for clear sky at 12.00 and cloudy sky at 21.00 on 19 February 2005. It is noted that all vertical profiles of three parameters, can distinguish aerosol and cloud layers and provide the optimal path length $(\xi)$ for $24 \mathrm{~h}$ AOD determinations. For clear sky condition in Fig. 3a, large depolarization ratio around 0.25 of the coarse aerosol particles is noticeable above $2.5 \mathrm{~km}$ high with a confirmation of sharp peak $\beta_{\mathrm{a}}$ at $2.8 \mathrm{~km}$ as the optimal path length $(\xi)$ for AOD determination. For cloudy sky in Fig. 3b, the sharp peaks of three parameters caused by multiple scattering from cloud base above $2.5 \mathrm{~km}$ is observed, giving the path length $(\xi)$ at $2.5 \mathrm{~km}$ with $\delta(\mathrm{z})$ less than 0.1 of existed fine soil dust aerosols.

Dataset of 4 consecutive days during 17-20 February 2005 representing the biomass burning contribution by the locals, was further investigated in order to monitor aerosol lifetime. Figure 4 shows daily temporal and height cross sections of $\delta(z)$ and $\beta_{a}(z)$ with color scales. The higher value $\delta(z)$ of coarse aerosol particles drifted in the atmosphere shows similar trend as discussed on Fig. 3a. This represents an evidence of aerosol loading caused by anthropogenic source which can be considered as a group of large emission of soot aerosols (carbonaceous aerosol as black and organic carbons) resulted from open burning of crop wastes in the immediate vicinity. Values of $\beta_{\mathrm{a}}$ (z) in the order of $10^{-5}$ and $10^{-6} \mathrm{~m}^{-1} \mathrm{sr}^{-1}$ are related to cloud and aerosol, respectively (Iokibe et al., 2005). In Fig. 4, the $\beta_{\mathrm{a}}(\mathrm{z})$ of $4 \times 10^{-6}-3 \times 10^{-5} \mathrm{~m}^{-1} \mathrm{sr}^{-1}$ with $\delta(\mathrm{z})$ of $4-5 \%$ illustrate the dark blue islands of lower coefficients of $\beta_{a}(z)$ in the green sea of higher $\beta_{a}(z)$. This implies that high value of obtained atmospheric column AODs were composed of a mixture of biomass burning and soil dust aerosols.

Finally, daily average of AODs $\left(\tau_{\mathrm{a}}\right)$ in the same period are reported in Table 1 with the minimum of 0.2187 and maximum of 0.4291 . These correlate to the continental polluted aerosol of 0.327 AOD, predicted by the software OPAC (Hess et al., 1998). Figure 5 shows both diurnal and nocturnal AODs in an attempt to display the specific appearances when the distinct evidences were observed. The aerosol populations are noticeable of high AODs up to 0.6-0.7 of larger size aerosol and later being declined during late nights. During 17-18 February 2005, there existed quite low AODs in comparison with the other two days, while their depolarization ratios were high due to coarse aerosols. Meanwhile, AODs were rather high on 19-20 February 2005 with low depolarization ratios due to dense fine aerosols. The prominence of open biomass burning emission during this period would result in short range aerosol transportation as seen in a day by day accumulation of fine and coarse aerosol particles. 

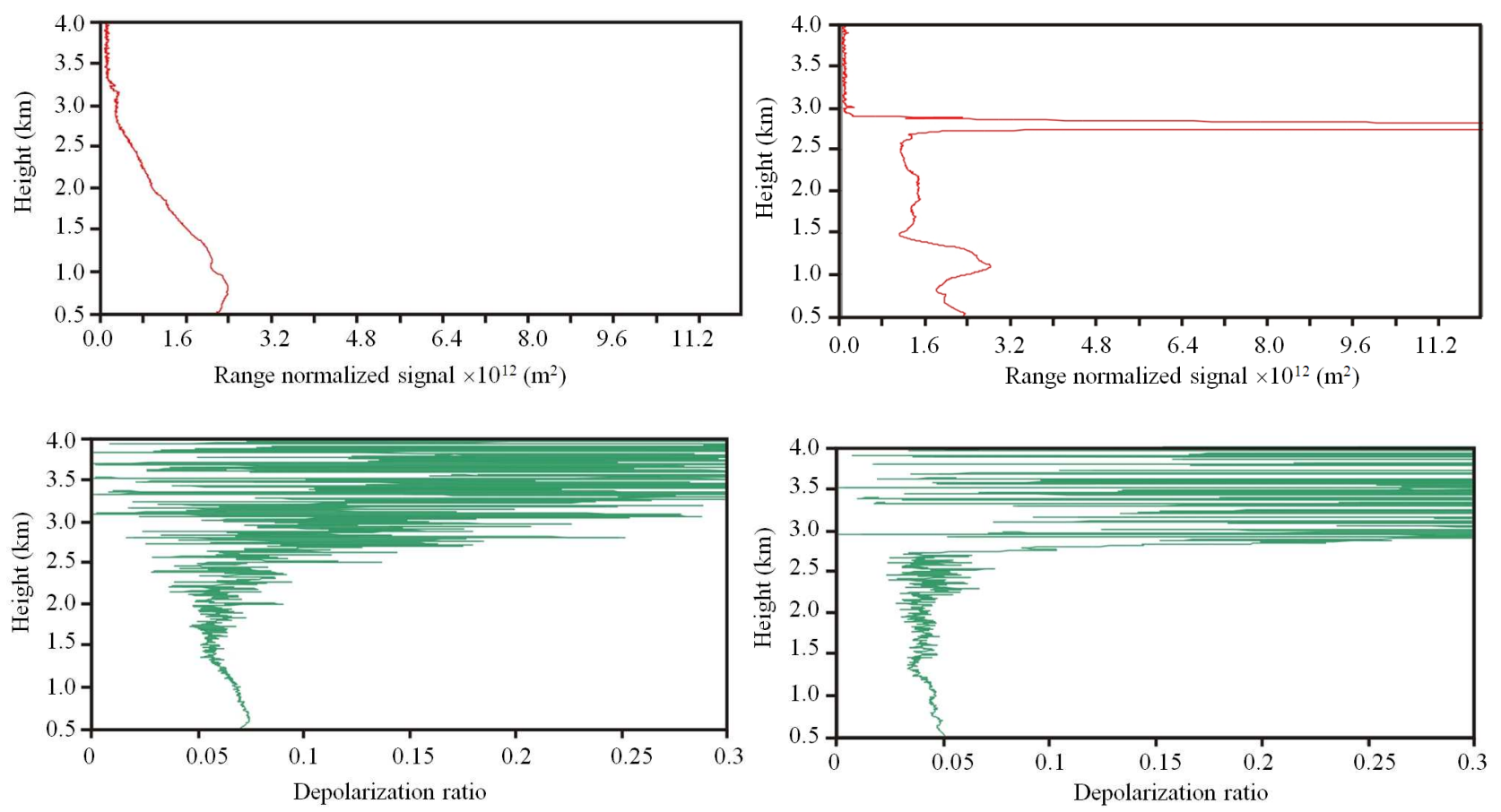

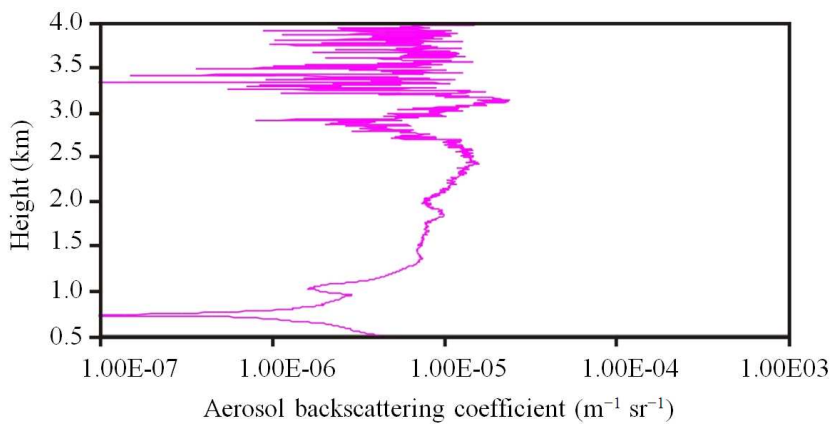

(a)

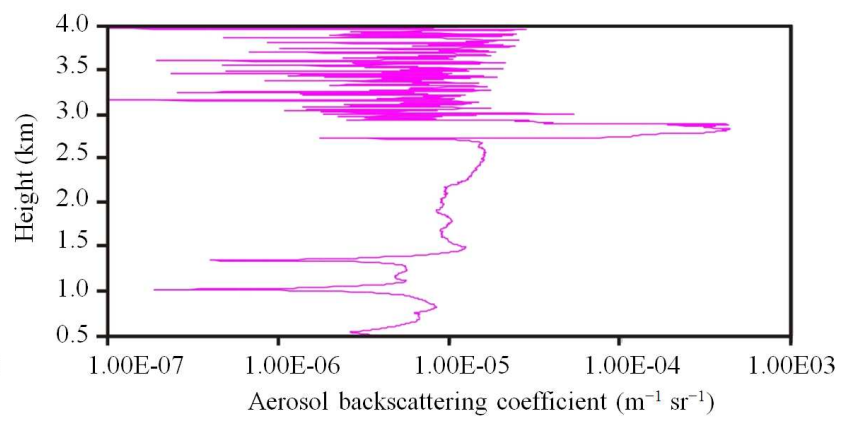

(b)

Fig. 3. The 19 February 2005 vertical profiles of range normalized signal, depolarization ratio and aerosol backscattering coefficients at: (a) 12.00 and (b) $21.00 \mathrm{LST}$, respectively

Table 1. Daily average of $\tau_{\mathrm{a}}$ for 4 consecutive days from 1720 February 2005

\begin{tabular}{lc}
\hline Date in February 2005 & Daily average of $\tau_{\mathrm{a}}$ \\
\hline 17 th & 0.2187 \\
18 th & 0.2437 \\
19 th & 0.4291 \\
20 th & 0.3326 \\
\hline
\end{tabular}

To be more specific, in the junctions of 3 adjacent days during 18-20 February 2005, the transports of aerosol appeared and AODs rose in the first half of the day, later dropped off during the midday and rose again in the afternoon so the same behavior did in the evening and late night. Importantly, from the 19-20 February 2005 results, it implied that the lifetime of biomass burning aerosols was slightly short within few hours since their depolarization ratios decreased from $18.00 \mathrm{pm}$ onwards. This caused by the effects of daily biomass burning emission due to farmer's routine behaviors and the practice of villagers to light open campfires for making warm and expelling insects during winter nights as being confirmed by each bump of high green depolarization ratios in Fig. 4. 


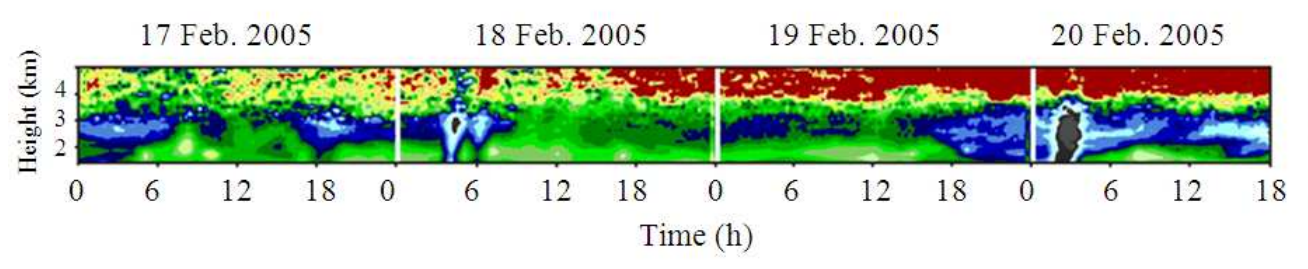

(a)

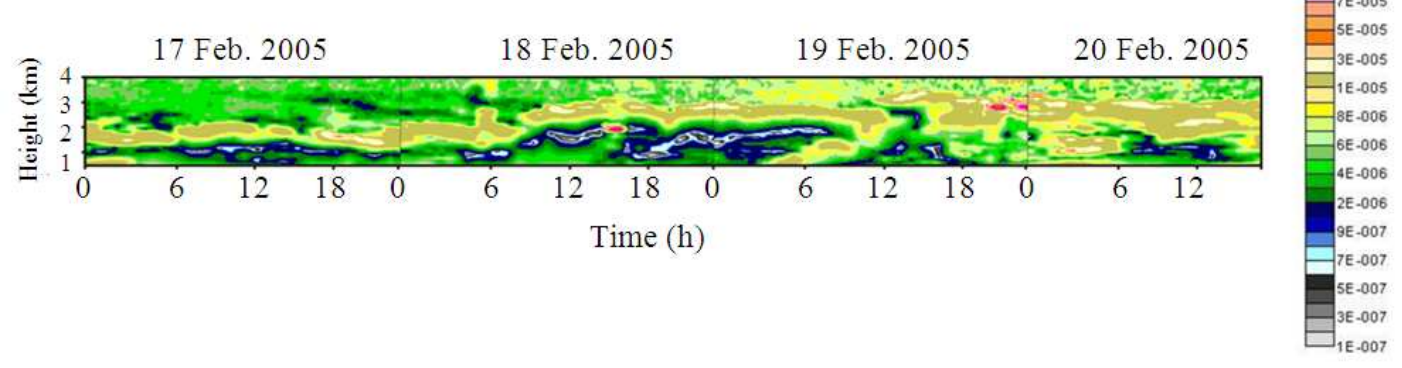

(b)

Fig. 4. Daily temporal and height cross sections of: (a) depolarization ratio and (b) aerosol backscattering coefficients on 17-20 February 2005 are shown with color scales

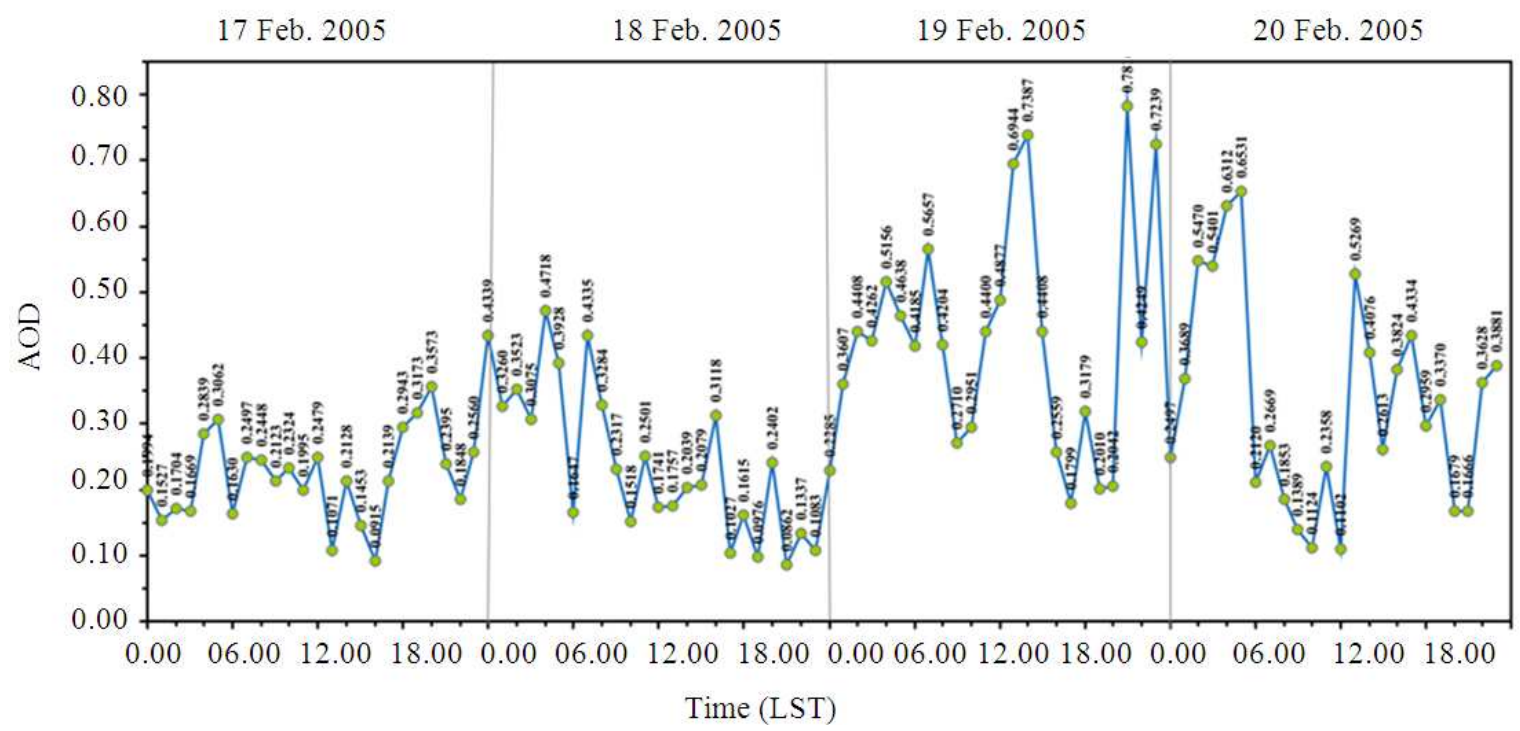

Fig. 5. $24 \mathrm{~h}$ atmospheric column of AODs retrieved from Mie lidar dataset for 4 consecutive days from 17-20 February 2005 
The obtainable results suggested that the lifetime of soot aerosols would last only for few hours when should possibly be the actual lifetime of aerosols. It might be under the influence of wind effect and nighttime high relative humidity yielding an increment of the extinction efficiency which had a partial effect on AOD enhancement.

\section{CONCLUSION}

In summary, the depolarization ratios of various periods are very interesting aspect for a classification of aerosol size distribution and cloud trend. The observation of either short lifetime or wind effect of carbonaceous and soil dust aerosols will be achievable if longer periods of retrievals are obtained. Yet, this work is preliminary for a validation of analytical retrieval algorithm and alternatively providing $24 \mathrm{~h}$ atmospheric column of AOD by the available Mie lidar at wavelength $532 \mathrm{~nm}$ in the region where aerosol data are sparse. It then would be useful for atmospheric science study in order to obtain the comprehension on aerosol characteristics in Thailand. For future work, we intend to create a software program for a custom lidar calculation especially for aerosol lidar ratio determination in order to profoundly study the characteristic of tropospheric aerosols in Thailand.

\section{ACKNOWLEDGEMENT}

The researchers are grateful to the National Institute for Environmental Studies of Japan and the Department of Geology, Faculty of Sciences, Chulalongkorn University for supporting all facilities and raw data. This study was funded by the King Mongkut's University of Technology Thonburi under the National Research University Project.

\section{REFERENCES}

Biral, A.R., 2003. Analysis of the 2002 Malargue lidar data through Fernald's method. Research report. UNICAMP, Brazil.

Fernald, F.G., 1984. Analysis of atmospheric lidar observations: Some comments. Applied Opt., 23: 652-653. DOI: 10.1364/AO.23.000652

Fernald, F.G., B.M. Herman and J.A. Reagan, 1972. Determination of aerosol height distributions by Lidar. J. Applied Meteor., 11: 482-489. DOI: $10.1175 / 1520$ 0450(1972)011<0482:DOAHDB > 2.0.CO;2
Hess, M., P. Koepke and I. Schult, 1998. Optical properties of aerosols and clouds: The software package OPAC. Bull. Am. Meteorol. Soc., 79: 831842. DOI: 10.1175/15200477(1998)079<0831:OPOAAC>2.0.CO;2

Iokibe, K., Y. Toyota, O. Wada and R. Koga, 2005. A scheme to classify clouds with the depolarization ratio and backscattering coefficient measured by Lidar. Memoirs Faculty Eng. Okayama Univ., 39: 93-101.

IPCC, 1995. Climate Change 1994: Radiative Forcing of Climate Change and an Evaluation of the IPCC Is92 Emission Scenarios. 1st Edn., Cambridge University, New York, ISBN-10: 0521559626, pp: 339.

Karyampudi, V.M., S.P. Palm, J.A. Reagen, H. Fang and W.B. Grant et al., 1999. Validation of the Saharan dust plume conceptual model using lidar, Meteosat and ECMWF data. Bull. Am. Meteor. Soc., 80: 1045-1075. DOI: $\quad 10.1175 / 1520$ 0477(1999)080<1045:VOTSDP>2.0.CO;2

Kim, S.W., S.C. Yoon, J. Kim and S.Y. Kim, 2007. Seasonal and monthly variations of columnar aerosol optical properties over East Asia determined from multi-year MODIS, LIDAR and AERONET Sun/sky radiometer measurements. Atmos. Environ., 41: 1634-1651. DOI: 10.1016/j.atmosenv.2006.10.044

Klett, J.D., 1985. Lidar inversion with variable backscatter/extinction ratios. Applied Opt., 24: 1638-1643. DOI: 10.1364/AO.24.001638

Linyan, B., X. Yong and G. Jie, 2008. Primary validation of the system aerosol retrieval model over Beijing area using aeronet data. Proceedings of the International Archives of the Photogrammetry, Remote Sensing and Spatial Information Sciences, (IAPRSSIS' 08), pp: 195-200.

Meehl, G.A., W.M. Washington, D.J. Erickson, B.P. Briegleb and P.J. Jaumann, 1996. Climate change from increased $\mathrm{CO}_{2}$ and direct and indirect effects of sulfate aerosols. Geophys. Res. Lett., 23: 3755 3758. DOI: 10.1029/96GL03478

Motoaki, Y., Z. Jixia, M. Kohei, I. Toshikazu, A. Tetsuo and L. Lichou, 2002. Observation of troposheric aerosol by using a Mie lidar: Observation at Arid Region in China. J. Commun. Res. Lab., 49: 233-242. 
NASA, 2001. Biomass Burning: A Hot Issue in Global Change. 1st Edn., Langley Research Center, Virginia, USA.

Pappalardo, G., A. Amondeo, S. Amoruso, L. Mona and M. Pandolfi et al., 2003. One year of tropospheric lidar measurements of aerosol extinction and backscatter. Ann. Geophys., 46: 401-413.

Qiu, J., 1998. A method to determine atmospheric aerosol optical depth using total direct solar radiation. J. Atmos. Sci., 55: 744-757. DOI: $10.1175 / 1520-$ 0469(1998)055<0744:AMTDAA > 2.0.CO;2

Reagan, J.A., M.P. McCormick and J.D. Spinhirne, 1989. Lidar sensing of aerosols and clouds in the troposphere and stratosphere. Proc. IEEE, 77: 433448. DOI: $10.1109 / 5.24129$

Reddy, M.S., O. Boucher and C. Venkataraman, 2002. Seasonal carbonaceous aerosol emissions from open biomass burning in India. Proceedings of the Annual Conference of Indian Aerosol Science and Technology Association, Space Physics Laboratory, Sept. 18-20, Vikram Sarabhai Space Center, Thiruvananthapuram, pp: 1-5.
Ruangrungrote, S., A. Intasorn and A. Chabangbon, 2008. Tropospheric aerosol volume backscattering coefficients determination using Mie lidar at Phimai district, Thailand. Proceedings of International Symposiam on Geoscience Resources and Environments of Asian Terranes, Nov. 24-26, Bangkok, Thailand, pp: 543-548.

Satheesh, S.K. and K.K. Moorthy, 2005. Radiative effects of natural aerosols: A review. Atmos. Environ., 39: 2089-2110. DOI: 10.1016/j.atmosenv.2004.12.029

Sugimoto, N., 2001. NIE Compact Mie scattering lidar (532 nm, dual polarization). National Institute for Environmental Studies of Japan. 